\title{
How do people with disabilities cope while waiting for disability insurance benefits?
}

\author{
Norma B Coe ${ }^{1 *}$, Stephan Lindner ${ }^{2}$, Kendrew Wong ${ }^{3}$ and April Yanyuan $\mathrm{Wu}^{4}$
}

\footnotetext{
* Correspondence: nbcoe@uw.edu 'School of Public Health, and NBER, University of Washington, 1959 NE Pacific Street, Seattle, WA 98195, USA

Full list of author information is available at the end of the article
}

\begin{abstract}
Disability Insurance waiting time varies from a few months to several years. We estimate the causal effect of longer waiting times on the use of five financial coping strategies. We find that SNAP benefits are the most responsive to longer waiting times. Moreover, while spousal employment is not responsive to longer wait times, spousal employment leads to longer waiting times, presumably because these applicants are more able to appeal. Together, these results suggest that coping strategies are used to both help applicants during the wait time and to extend the waiting time and increase their probability of success.

JEL Classification Code: H53; J08; 13

Keywords: Social security disability insurance; Waiting time; Disability; Instrumental variables; Supplemental Nutrition Assistance Program (SNAP); Added worker effect
\end{abstract}

\section{Introduction}

A worker with disabilities seeking Social Security Disability Insurance (SSDI) benefits must first undergo a multi-layered and potentially lengthy disability determination process. Approximately one-third of SSDI applicants are awarded benefits during the first stage of the application process, with an average processing time of 4.3 months; for those few who appeal all the way through to the deferral courts, the average processing time is 57 months (Autor and Duggan 2010). During the application and appeals processes, SSDI applicants receive no income support or medical benefits from the SSDI program. However, they face strong incentives to remain out of the labor force because evidence of gainful employment would disqualify their application ${ }^{1}$.

While considerable attention has been paid to how health insurance coverage and earnings change after disability onset, much less is known about how individuals with disabilities fund their consumption during the application process. Two notable exceptions include Bound et al. (2003) and Honeycutt (2004). Both papers find that income from government transfers and temporary disability insurance programs partially offset the decline in SSDI applicants' own labor earnings. However, while the wait time for SSDI has drawn increased attention from research and the policy-making arenas, the relationship between waiting time and how individuals fund consumption remains unexplored.

Using the 1990 to 2008 Survey of Income and Program Participation (SIPP) linked to the Social Security Administration's (SSA) 831 file, this paper is the first to examine 
the causal relationship between the waiting time and various coping strategies of applicants for SSDI. Our analysis starts with documenting the evolution of applicants' income and sources of income before and during SSDI application. The study focuses on five types of coping strategies that applicants may rely on, including: (1) government transfers: Supplemental Nutrition Assistance Program (SNAP); Workers' Compensation; and Unemployment Insurance $(\mathrm{UI})^{2}$, (2) employment and earnings of the spouse, (3) changing living arrangements, (4) borrowing from credit, and (5) liquidation of housing assets ${ }^{3}$.

We then examine how wait time is associated with the use of each coping strategy in the initial month of application and the average use of each coping strategy over the duration of the application. We also investigate how the use of each coping strategy changes with time since application, controlling for the overall application duration using fixed effects. While this estimation strategy addresses some endogeneity concerns, the correlation between the time since application and the use of a coping strategy could be due to either causation (applicants reacting to a longer waiting time) or reverse causation (applicants using the coping strategy to fund a longer waiting time by appealing an initial denial). To separate these two effects, we employ an Instrumental Variable (IV) approach, using the average waiting time by state-year-stage to instrument for the actual waiting time, to identify the effect of an exogenous increase in the waiting time on the use of each coping strategy ${ }^{4}$.

The findings can be summarized as follows. First, while the correlation between the wait time and the use of any particular coping strategy, during the initial month or on average over the spell, is largely absent, we find that applicants with an exogenously longer waiting durations are more likely to use SNAP benefits both initially and on average, and less likely to change one's address over the duration of the application. Longer wait times are negatively correlated with the probability that applicants receive UI benefits in an average month over the spell, likely because these benefits cease after several months. Finally, we find a positive relationship between the time since application and spousal employment in the fixed effect model but no such relationship for our IV regressions. Together, these results suggests that applicants' spouses do not react to an exogenous increase in the waiting time by working more, but that a working spouse makes it more likely that applicants extend the waiting time by appealing an initial denial.

The paper proceeds as follows. Section 2 briefly outlines SSDI and reviews the existing literature. Section 3 describes the data and sample construction and presents descriptive statistics. Section 4 provides an overview of coping strategies and the determination of eligibility and take-up for each strategy. Section 5 describes how the wait time is correlated with demographic characteristics, coping strategies used at the time of application and over time as application progresses. Section 6 discusses the econometric approach and Section 7 summarizes the main results, followed by concluding remarks in Section 8.

\section{Background}

\section{Social security disability insurance}

SSDI is a social insurance program that provides cash benefits to workers who face a work-limiting disability expected to last at least 12 months or until death. Individuals must have worked long enough and recently enough to be SSDI-insured; that is, one 
must have worked an age-specific number of quarters and have worked 20 quarters in the last 10 years ${ }^{5}$. SSDI-insured individuals are eligible for SSDI benefits if they are not currently earning more than the Substantial Gainful Activity (SGA) level due to a disability and are expected to be unable to do so for at least a year. SSDI benefits are a function of an individual's past labor earnings, using the same formula as Social Security retirement benefits, without an actuarial adjustment for early receipt of benefits. Individuals with disabilities who do not medically recover will get their full Social Security retirement benefit in perpetuity, as if they had retired at their Full Retirement Age ${ }^{6}$.

\section{SSDI application process}

The application process has five stages: First, applicants must not have engaged in substantial gainful activity (SGA) since disability onset, where SGA is defined as earnings above a threshold ( $\$ 1,010 / \$ 1690$ per month for the non-blind/blind applicants in 2012). Applications screened out at this stage are labeled "technical denials," do not receive a medical review, and are not observed in our data. All other applications are sent to a state Disability Determination Service (DDS) center, where cases are assigned to disability examiners for review on a rotational basis ${ }^{7}$. These applications are determined at one of the following four sequential stages:

(2) Whether the health condition is severe;

(3) Whether the condition is included in the list of disabling conditions;

(4)If neither 2 nor 3, whether the person can do their previous work;

(5) Whether the person can do any other type of work ${ }^{8}$.

Due to the sequential nature, each additional stage increases wait time.

Overall, only about one-third of all applications are accepted at these stages. Applicants denied benefits at this point can appeal, first to the same DDS center that made the original determination, then to an Administrative Law Judge (ALJ). Notably, ALJs overturn SSA's initial rejections in approximately 75 percent of the cases they hear, but there is substantial variation across ALJs in the award rate (French and Song 2009). Rejected applicants can then appeal to the central Appeals Board of Washington and finally to a federal court. Because of the relatively low initial allowance rate and these lengthy appeals processes, the mean determination time for allowed applicants significantly exceeds that of denied applicants (Autor et al. 2011). Hence, the many stages of initial determination and subsequent adjudication mean that the application for SSDI benefits can potentially take years.

Even if two applicants are identical in their application/appeals process, the wait time for an SSDI award can vary by the state in which an individual lives and the year during which the application is filed. Applicants living in Alabama, Illinois, Indiana, Michigan, Minnesota, Missouri, Nebraska, Ohio, Wisconsin and the District of Columbia face the longest wait times; Connecticut, Delaware, Hawaii, Maine, Louisiana, Massachusetts, Oklahoma, Texas, Utah and West Virginia residents face the shortest (Allsup 2010). There also has been variation in wait times over time. The time lag between application and decision has been growing and recent interventions by SSA have tried to address this trend, for example, by nationwide usage of the Quick Disability Determination (QDD) process or creation of additional ALJ positions and National Hearing Centers. Twenty-four of the 46 states with 
hearing offices saw a reduction in wait times in 2010 compared with 2008. The SSA reports that the national average processing time for a hearing decision in 2010 was 442 days, down from 514 days in September 2008 (Social Security Administration 2010). Similarly, the total hearings backlog has decreased by more than 71,000 cases since December 2008 (Allsup 2010).

For our analysis, we use changes in the wait time by initial determination stages as a source of exogenous variation in the wait time. To understand the magnitude of this variation, Table 1 displays the distribution of the average waiting time by application stage for all states and three large states (California, New York, and Texas) for the years 1990-2010. Minimum and maximum refer to the longest and shortest average wait time during these years. Stage three applications have on average the shortest duration and the least variation, since applicants with a listing condition are allowed onto the program. Average application times are longer and have more variation for the other stages, primarily because of appeals process extending wait times. Comparing minimum, average and maximum application durations, one can see a substantial variation in waiting times within a stage and state. For instance, the minimum average waiting time for stage two applications in California is about 4 months and the maximum is about 8 months - a 100 percent difference.

\section{Literature review}

Recent work on the duration of the SSDI application process has estimated the causal effects on applicants' subsequent employment. Specifically, Autor et al. (2011) find that the SSDI determination process directly reduces the post-application employment of

Table 1 Distribution of waiting time by application stage

\begin{tabular}{lcccc}
\hline & Mean & Std. Dev. & Minimum & Maximum \\
\hline Stage 2 & & & & \\
All & 4.99 & 1.05 & 2.80 & 5.68 \\
New York & 4.68 & 0.52 & 3.58 & 8.47 \\
California & 5.51 & 1.06 & 4.07 & 5.95 \\
Texas & 4.98 & 0.44 & 4.31 & \\
Stage 3 & & & & 7.52 \\
All & 3.93 & 0.71 & 2.43 & 4.36 \\
New York & 3.50 & 0.38 & 2.81 & 5.52 \\
California & 4.06 & 0.55 & 3.48 & 4.58 \\
Texas & 4.00 & 0.29 & 3.57 & \\
Stage 4 & & & 14.77 \\
All & 6.02 & 1.36 & 3.48 & 6.46 \\
New York & 5.10 & 0.82 & 3.82 & 9.39 \\
California & 1.18 & 4.56 & 6.93 \\
Texas & 6.25 & 0.50 & 5.09 & 6.15 \\
Stage 5 & 5.85 & & & 6.97 \\
All & & 1.15 & 3.58 & 3.83 \\
New York & 5.78 & 0.72 & 4.61 & \\
California & 5.12 & 0.87 & 4.77 & \\
Texas & 5.82 & 0.56 & & \\
\hline Notes: The & 5.72 & & & \\
\hline
\end{tabular}

Notes: The table displays waiting time in months for all states and selected states by application stage for the period 1990-2010. 
denied applicants by approximately 3.6 percentage points ( 7 percent) and allowed applicants by approximately 5.2 percentage points (33 percent). Considerable attention has also been paid to how applicants fill the health insurance coverage gap during the 29-month waiting period for Medicare benefits (for example, Dale and Verdier 2003; Riley 2006; Livermore et al. 2009). The evidence suggests that SSDI applicants have lower health insurance coverage rates for up to three years before application than non-applicants, and one-quarter of SSDI beneficiaries go uninsured during the waiting period.

Also related to this work are studies that find a strong earnings decline at and after onset of a disability. Schimmel and Stapleton (2012) compare individuals who experience a work limitation to individuals who are observationally identical prior to disability onset. They find that earnings declined by 50 percent within two years after onset of a work limitation and alternative income sources such as UI benefits can only partially offset the decline of earnings. The similar magnitude of the decline in earnings is also reported by Dushi and Rupp (2013). Moreover, Meyer and Mok (2013) report that earnings fall by almost 80 percent during the ten years following a disability onset compared to 5 years before the disability onset.

Because of this strong earnings decline and the fact that applicants receive no income or medical benefits until their case has been decided, SSDI applicants have fewer financial resources to fund consumption during the application process. However, little is known about what these individuals with disabilities live on before receiving SSDI benefits. Honeycutt (2004) finds that a large proportion of new SSDI beneficiaries receive workers compensation, employer disability, retirement income, and food stamps before obtaining SSDI benefits. Bound et al. (2003) further our understanding by looking not just at beneficiaries but all SSDI applicants. Using an unbalanced panel, they examine income sources three years before, at SSDI application, and three years after application. They find that earnings, and to a lesser extent total household income, drop dramatically six months prior to SSDI application, but rebound during the subsequent three-year period. In the early months following SSDI application, a patchwork of temporary disability benefits offset declines in SSDI applicants' own labor earnings. In the long run, most of these temporary sources of income decline and are replaced by SSDI benefits for successful applicants or earnings for denied applicants.

Although these studies shed light on how people might use other income sources as a coping strategy, it is unclear whether applicants for SSDI rely on other coping strategies more as they experience a longer waiting time, or whether they use other income sources to extend their waiting time, primarily by filing an appeal. The main contribution of this study to this literature is to compare both ordinary least squares (OLS) and IV estimates to parse out the causal relationship between various coping strategies and the waiting time. Moreover, we use more recent data and expand the list of coping strategies studied that may be available to applicants.

\section{Data, Sample, and Descriptive Statistics}

Data

This study uses data from the SSA's 831 file linked to household information from SIPP panels starting in 1990-2008. The SIPP is a nationally-representative longitudinal survey of households conducted by the U.S. Census Bureau. The main objective of the 
SIPP is to provide comprehensive information about income and program participation of individuals and households in the United States. Every four months over a two- to four-year period, respondents are asked a battery of questions on their labor market participation, sources of income, employment relationships, demographics and family structure, health insurance status, wealth, and public program participation during each month between interviews. New panels began annually between 1990 and 1993, plus 1996, 2001, 2004, and 2008. The SIPP panel is a useful data set for measuring changes in short term economic well-being.

The SSA's 831 file is the official disability determination data used by the Disability Determination Services. When a person applies for SSDI or Supplemental Security Income (SSI), an 831 file is opened. We use 831 records to identify the date of the first application and the type of application (SSDI vs. SSI). The 831 record subsequently tracks the application through the initial determination and up to reconsideration level ${ }^{9}$. To improve the accuracy of application outcomes, 831 files are augmented with the Master Beneficiary Records (MBR) and the Payment History Update System (PHUS). MBR and PHUS records contain complete application and determination information, and are matched to 831 files using application and benefit begin dates, respectively.

The matched data have the advantage of administrative information on SSDI application and receipt that is more accurate than self-reports, plus household and individual characteristics that are not usually available in administrative records. The long time span of the data allows us to examine changes over time.

\section{Sample}

The sample for this analysis includes individuals who are matched to Social Security data (they either disclose their Social Security Number or have a match based on name, birth date, and address so that they can be matched to 831 file) and who applied for SSDI while being surveyed by the SIPP. We also restrict our sample to individuals age 18 to 66 at the time of SSDI application. We focus our analysis on months during which an application is pending, i.e., months between the month of filing a claim and the month of final determination. Person-month observations after SSDI benefits awarded are excluded from the analysis. These restrictions result in a sample of 4,594 SSDI applicants with 26,136 person-month observations.

Our sample respondents may have multiple disability applications in the years covered by the administrative data. We focus on the first application we observe in the administrative data to be sure we can observe income and its sources in the SIPP before and during application for SSDI benefits. While the vast majority (85.4 percent) of our sample contains complete information on the first application process, some cases are pending within the SIPP and thus we do not observe the entire application period. For these cases, we are able to obtain the application duration and determination information from the administrative data, but we do not have associated time-varying demographics, income amounts or sources, or information related to coping strategies for applications months that are not covered by the SIPP panel. Moreover, this rightcensoring is more likely to affect individuals with longer application durations compared to individuals with shorter durations, as well as more recent (2008) panelists. If individuals with different application durations differ systematically in terms of both 
observable and unobservable characteristics, right-censoring may potentially create biases for our analysis. To address this issue, we run a sensitivity analyses on the subsample for which we observe the entire application period.

One important limitation of our data is that we can only identify applications for SSDI of SIPP respondents who can be matched to administrative records. Bound et al. (2010) present matching rates by SIPP survey and differences in demographic characteristics between matched and non-matched SIPP respondents. Non-disclosure rates are 10-15 percent during the SIPP 1990 panels but increase for the 2001 and 2004 SIPP panels and giving permission to link is nonrandom; matched SIPP respondents tend to be older, more educated, more likely to be married and to work, and less likely to report a work limitation. These differences imply that our sample is not fully representative of the entire SSDI application population. Differences between matched and non-matched records also suggest that non-matched SIPP respondents have higher SSDI application rates. Although imperfect matching poses a limitation to the generalizability of our study, it is important to note that using SIPP surveys matched to administrative records is currently the only feasible approach to conduct a comprehensive analysis of coping strategies for SSDI applicants.

\section{Descriptive statistics}

Table 2 presents averages for the socioeconomic characteristics of SSDI applicants measured at the month of application. The average age of applicants is 45 , slightly more than half are male, and slightly more than three-quarters are white. Educational attainment is roughly evenly distributed between high school drop-outs, high school graduates, and those who have at least some college. Half of all applicants are married at the time of application. On average, household income of just over \$3,000 per month supports almost three people. A quarter of applicants have worked in the month of application. Almost half of all applicants apply for both SSDI and SSI, suggesting that these applicants do have relatively strong attachment to the labor force - they have worked enough to be insured by SSDI - but remain low-income - their income and assets are low enough that they qualify for SSI benefits.

These demographic characteristics compare relatively well to nationally representative statistics. For instance, Lindner (2013) analyze the universe of SSDI applicants between 1991 and 2008 and report an average age of 45.5 at application. He also finds that 51.3 percent of SSDI applicants apply for SSI. Our wait time is about one month higher than the average wait time reported in his work, presumably because we measure the wait time in SIPP survey months and not in exact days ${ }^{10}$. Moreover, the 2012 Statistical Supplement reports that 56 percent of all new SSDI beneficiaries between 1990 and 2010 were male, close to the 53.8 percent reported here ${ }^{11}$.

There are numerous differences in demographic characteristics of our sample and that of Bound et al. (2003). Our sample of SSDI applicants is more likely to be female and a high-school drop-out, and less likely to be married, and have larger household size but lower household income. These differences in sample characteristics can largely be explained by changes in applicants over time. Table 3 compares applicants of the 1990s to applicants of the 2000s. The starkest difference is the gender composition: 55 percent of applicants were male in the 1990s but only 47 percent are in the 2000s. This is likely due to the shift towards more labor market activity among women, which 
Table 2 Descriptive statistics of SSDI applicants, at the month of application

\begin{tabular}{|c|c|c|}
\hline & \multicolumn{2}{|c|}{ Month of application } \\
\hline & Mean & Standard deviation \\
\hline Age & 45 & 0.29 \\
\hline Male & 53.8 & 1.20 \\
\hline \multicolumn{3}{|l|}{ Race } \\
\hline White & 78 & 0.92 \\
\hline Black & 19.5 & 0.88 \\
\hline Other & 2.5 & 0.33 \\
\hline \multicolumn{3}{|l|}{ Education } \\
\hline High-school drop-out & 31.6 & 1.02 \\
\hline High-school graduate & 37.3 & 1.06 \\
\hline Some college & 31 & 1.06 \\
\hline \multicolumn{3}{|l|}{ Marital status } \\
\hline Married & 50.4 & 1.11 \\
\hline Divorced & 25.4 & 0.96 \\
\hline Single & 19.2 & 0.96 \\
\hline \multicolumn{3}{|l|}{ Family/household structure } \\
\hline Family size & 2.7 & 0.04 \\
\hline Household size & 2.9 & 0.04 \\
\hline Number of kids in family & 0.7 & 0.02 \\
\hline \multicolumn{3}{|l|}{ Employment } \\
\hline Employed this month & 25.1 & 0.94 \\
\hline \multicolumn{3}{|l|}{ Income } \\
\hline Income (person) & 1,063 & 42.61 \\
\hline Income (household) & 3,086 & 69.47 \\
\hline Earnings (monthly, person) & 415 & 27.60 \\
\hline Earnings (household) & 2,071 & 59.09 \\
\hline \multicolumn{3}{|l|}{ SSDI } \\
\hline Application right-censored & 14.6 & 0.78 \\
\hline Application duration & 6.6 & 0.33 \\
\hline Joint SSDI/SSI application & 47.8 & 1.11 \\
\hline $\mathrm{N}$ & 4,594 & \\
\hline
\end{tabular}

makes them relatively newly eligible for the SSDI program ${ }^{12}$. The educational background of applicants has also changed significantly, with the proportion of applicants without a high school degree dropping from one-third to one-fifth, likely mirroring overall trends in education during this time period ${ }^{13}$. Applicants in the 2000 s are also less likely to be married, and while their monthly earnings and household incomes are similar, personal income is lower among the more recent applicants.

\section{Overview of coping strategies}

We examine the following strategies SSDI applicants use to fund consumption while waiting: (1) government transfers, including SNAP, UI, and workers' compensation; (2) earnings of the spouse; (3) changing living arrangement; (4) borrowing from credit cards; (5) liquidation of housing assets. Given the complexity of these programs, we 
Table 3 Descriptive statistics of SSDI applicants, 1990s vs. 2000s, at the month of application

\begin{tabular}{|c|c|c|c|c|}
\hline & \multicolumn{2}{|r|}{$1990 \mathrm{~s}$} & \multicolumn{2}{|r|}{$2000 s$} \\
\hline & Mean & Standard deviation & Mean & Standard deviation \\
\hline Age & 45.1 & 0.3 & 44.4 & 0.85 \\
\hline Male & 55.2 & 1.28 & 47.2 & 3.02 \\
\hline \multicolumn{5}{|l|}{ Race } \\
\hline White & 78.1 & 1.03 & 77.8 & 2.01 \\
\hline Black & 19.4 & 0.99 & 20.1 & 1.94 \\
\hline Other & 2.5 & 0.37 & 2.1 & 0.6 \\
\hline \multicolumn{5}{|l|}{ Education } \\
\hline High-school drop-out & 33.8 & 1.15 & 21.7 & 2.03 \\
\hline High-school graduate & 37.7 & 1.17 & 35.7 & 2.44 \\
\hline Some college & 28.6 & 1.09 & 42.6 & 2.9 \\
\hline \multicolumn{5}{|l|}{ Marital status } \\
\hline Married & 51 & 1.21 & 47.7 & 2.75 \\
\hline Divorced & 25.4 & 1.07 & 25 & 2.12 \\
\hline Single & 18.5 & 0.97 & 22.5 & 2.95 \\
\hline \multicolumn{5}{|l|}{ Family/household structure } \\
\hline Family size & 2.7 & 0.05 & 2.6 & 0.09 \\
\hline Household size & 2.9 & 0.05 & 2.9 & 0.07 \\
\hline Number of kids in family & 0.7 & 0.03 & 0.7 & 0.05 \\
\hline \multicolumn{5}{|l|}{ Employment } \\
\hline Employed this month & 24.8 & 1.05 & 26.4 & 2.18 \\
\hline \multicolumn{5}{|l|}{ Income } \\
\hline Income (person) & 1,087 & 49.44 & 954 & 70.1 \\
\hline Income (household) & 3,093 & 76.91 & 3,057 & 161.5 \\
\hline Earnings (monthly, person) & 415 & 31.6 & 417 & 51.96 \\
\hline Earnings (household) & 2,051 & 65.29 & 2,164 & 139.84 \\
\hline \multicolumn{5}{|l|}{ SSDI } \\
\hline Application right-censored & 13.6 & 0.83 & 19.5 & 2.19 \\
\hline Application duration & 6.7 & 0.38 & 5.9 & 0.55 \\
\hline Month of first benefit payment & -12.7 & 0.63 & -12.6 & 0.82 \\
\hline Joint SSDI/SSI application & 47.8 & 1.21 & 47.6 & 2.8 \\
\hline N & 2,058 & & 2,536 & \\
\hline
\end{tabular}

briefly discuss rules and regulations that are relevant for this study and how eligibility for each coping strategy is determined. Table 4 summaries the use of each coping strategy at the time of application ${ }^{14}$.

\section{The supplemental nutrition assistance program}

The SNAP is the largest nutrition program for low-income Americans and a mainstay of the federal safety net. To receive SNAP, households must meet three financial criteria: a gross-income test, a net-income test, and an asset test. A household is automatically or "categorically" eligible for SNAP through the receipt of SSI, Temporary Assistance for Needy Families (TANF), or General Assistance benefits. SSI and SSDI 
Table 4 The use of coping strategies at the month of application

\begin{tabular}{lcc}
\hline & \multicolumn{2}{c}{ Month of application } \\
\cline { 3 - 3 } & Mean & Standard deviation \\
\hline Government transfers & 18.2 & 0.43 \\
SNAP recipiency & 5.3 & 0.67 \\
UI recipiency & 6.8 & 0.54 \\
Workers' compensation recipiency & & \\
Intra-family resources & & 1.45 \\
Spousal labor supply & 62.7 & 80.48 \\
$\quad$ Employment & 2775 & \\
$\quad$ Earnings & & 0.82 \\
Other financial resources & & 278.64 \\
Borrowing from credit cards & 17.1 & 1.11 \\
$\quad$ Fraction & 3451.1 & \\
$\quad$ Amount & 58.8 & 0.41 \\
Home ownership & & \\
Locational changes & 4.1 & \\
Changed address & 4594 & \\
$\mathrm{~N}$ & & \\
\hline
\end{tabular}

benefits are part of gross household income. The amount of SNAP benefit that a household receives is equal to the maximum benefit level less 30 percent of the household's net income (reflecting the assumption that an average household will spend approximately 30 percent of its net income on food). We focus on the use of SNAP among SSDI applicants ${ }^{15}$. Overall, 18 percent of our sample report receiving SNAP benefits at the month of SSDI application (Table 4).

\section{Unemployment insurance}

UI is a federal-state partnership providing short-term cash benefits to individuals who lose their jobs through no fault of their own, i.e. either involuntarily or voluntarily with a good cause (e.g. due to illness). Unemployed workers are eligible for UI benefits if they fulfill all monetary and non-monetary requirements. Monetary entitlement requires sufficiently high wage earnings during the first four of the last five completed calendar quarters before the worker files a claim. Non-monetary eligibility criteria concern both the reason for job separation and ongoing claims. Weekly UI benefit formulas specify a minimum and a maximum benefit amount as well as a percentage within these boundaries. The duration of benefits is either set at a fixed level for all UI recipients (nine states), or depends on the total amount of benefits unemployed workers can receive during their eligibility period. Since we cannot infer the reasons for a job separation from the survey and we are not able to determine the exhaustion of UI benefits, our analysis focuses on UI recipiency. About 5 percent receive UI benefits at the time of application.

\section{Workers' compensation}

Workers' compensation is a state-mandated insurance program that provides compensation to employees who suffer job-related injuries and illnesses. Each state has its own 
laws and programs. Independent contractors are not entitled to workers' compensation. Since we do not know where an injury occurred, we are not able to determine the eligibility for workers' compensation. Overall, nearly 7 percent receive benefits, which is comparable to the literature (Social Security Administration, 2010).

\section{Changing living arrangement}

SSDI applicants could cut expenses by changing their living arrangements, such as moving into relatives' house or into lower-costs housing. The only variable that is available from the SIPP on this dimension is whether respondents change addresses. Overall, 4 percent changed their address between the month before and the month of application. This is much higher than the average move rate ${ }^{16}$.

\section{Spousal insurance}

The interaction of couple's labor supply has been widely discussed in the literature (Heckman 1974, for example). Couples can self-insure through intra-family labor market substitution; i.e., if one person cannot work, the other spouse can enter the labor market or earn more. This is often referred to as the added-worker effect. We measure this strategy by examining: 1) changes in marital status; 2) employment and changes in employment of the spouse; 3) earnings and changes in earnings of the spouse. At the time of application, over 60 percent of spouses are working, and the average earnings among employed spouses are $\$ 2,775$ per month.

\section{Borrowing from credit cards}

An SSDI applicant can also borrow from credit cards to fund consumption while their application is pending. Overall, 17 percent of SSDI applicants have an outstanding balance from credit cards in the month of application, which is lower than the 20 percent for the overall SIPP sample of the same age $(t=6.5)$. Among applicants with a credit card balance, the average balance is $\$ 3,451$ and the median is $\$ 1,421$.

\section{Liquidation of housing assets}

SSDI applicants who own a home also can partially or fully liquidate housing assets to support the consumption. Unfortunately, only information on home ownership is available from the SIPP; therefore, we will not be able to measure partial liquidation, such as borrowing from home equity line of credit. About 61 percent of the sample own a house 12 months prior to application, and only 59 percent at the time of application are home owners.

\section{The use of coping strategies before, at, and after application}

The average application duration is over 6 months, or approximately 200 days, but wait times are quite skewed to the left, as depicted by Figure 1 . Specifically, the $25^{\text {th }}$ percentile is 60 days, the median wait time is 101 days, and the $75^{\text {th }}$ percentile is 152 days. The right tail is also quite long, with 12 percent of the sample waiting at least one year, and 5 percent of the sample waiting more than two years.

Table 5 presents descriptive statistics at the month of application by total application duration. The first group of applicants has to wait up to 3 months before a final determination was reached; the corresponding waiting time for the second, third and the 


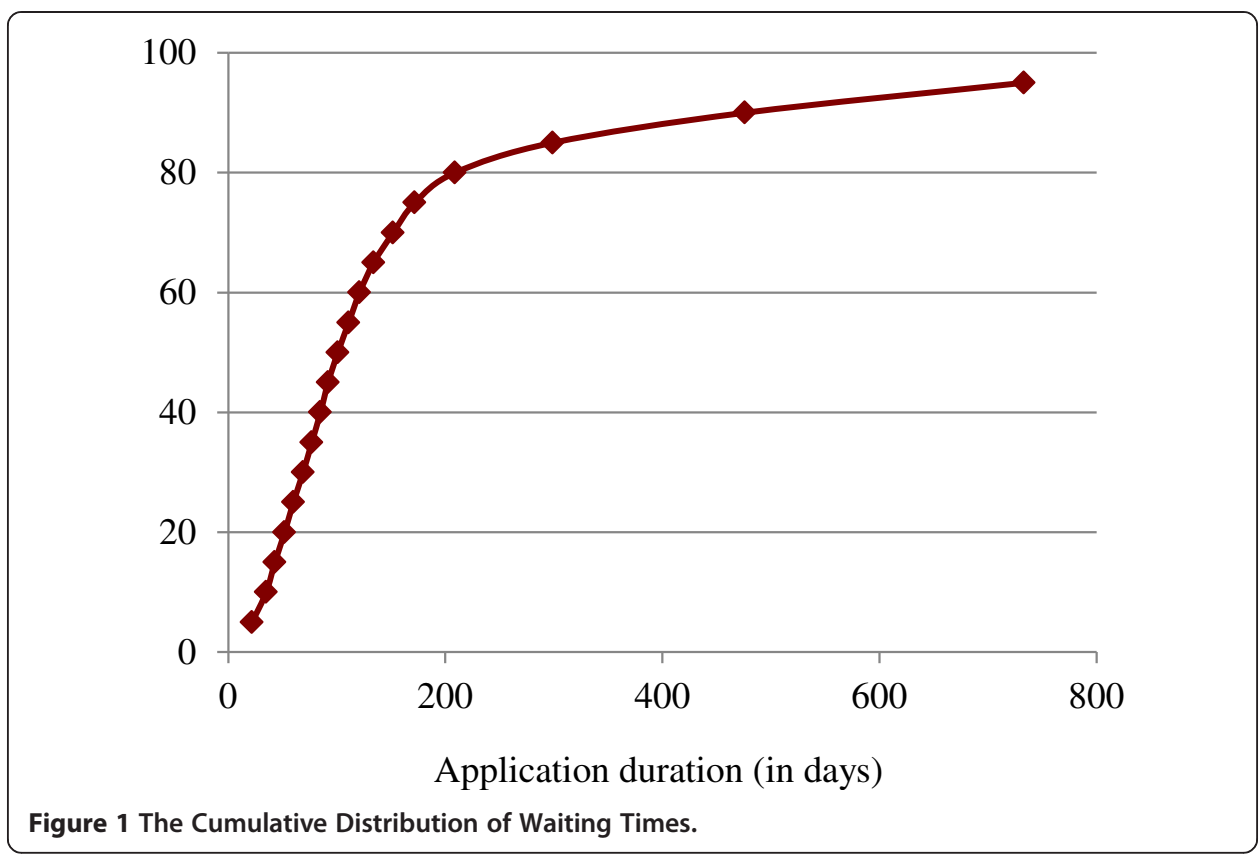

fourth group is 4 to 6 months, 6 to 12 months, and more than a year, respectively. SSDI applicants with less than 3 months of wait-time are more likely to be male or whites and less likely to be divorced, while those who wait longer than 6 months are more likely to be single. There are a few characteristics that show a U-shaped pattern - there is a decreasing trend between no wait and up to 12 months of wait-time, but then reversing the trend among those who wait longer than 12 months before their final determination. For example, the average income is $\$ 1,116$ per month for applicants whose case is determined within the first three months of applications. Average income slowly decreases as the wait time increases, to $\$ 846$ per month for those waiting between 6-12 months. However, among those whose case takes longer than 12 months to decide, their average income is back up to over $\$ 1,000$ per month. This same pattern holds for employment, income household level and earnings at both the personal and household level, as well as percent married. We also find that joint SSDI/SSI application exhibits an inverse U-shaped pattern: about 46 percent for applications who wait less than 3 months; the fraction peaks at 54 percent for those waiting between 4-6 months, then declines to 41 percent among those wait for more than 12 months.

Much like with demographics, the correlations between using a certain coping strategy at the month of application and the wait time is not monotonic (Table 6). SSDI applicants who wait for longer than 6 months are less likely to use UI benefits, but more likely to receive workers' compensation. While both spousal employment and home ownership show a U-shaped pattern with the application duration, the share borrowing from credit cards and changing address exhibit an inverse $\mathrm{U}$-shape.

Although we cannot detect much of a relationship between the initial use of coping strategies and the overall wait time through examining the means (Table 6), it is quite possible that the use of certain coping strategies changes as time since application progresses. We next explore how applicants use coping strategies in the months before and after their SSDI application. 
Table 5 Descriptive statistics of SSDI applicants, by application duration, at the month of application

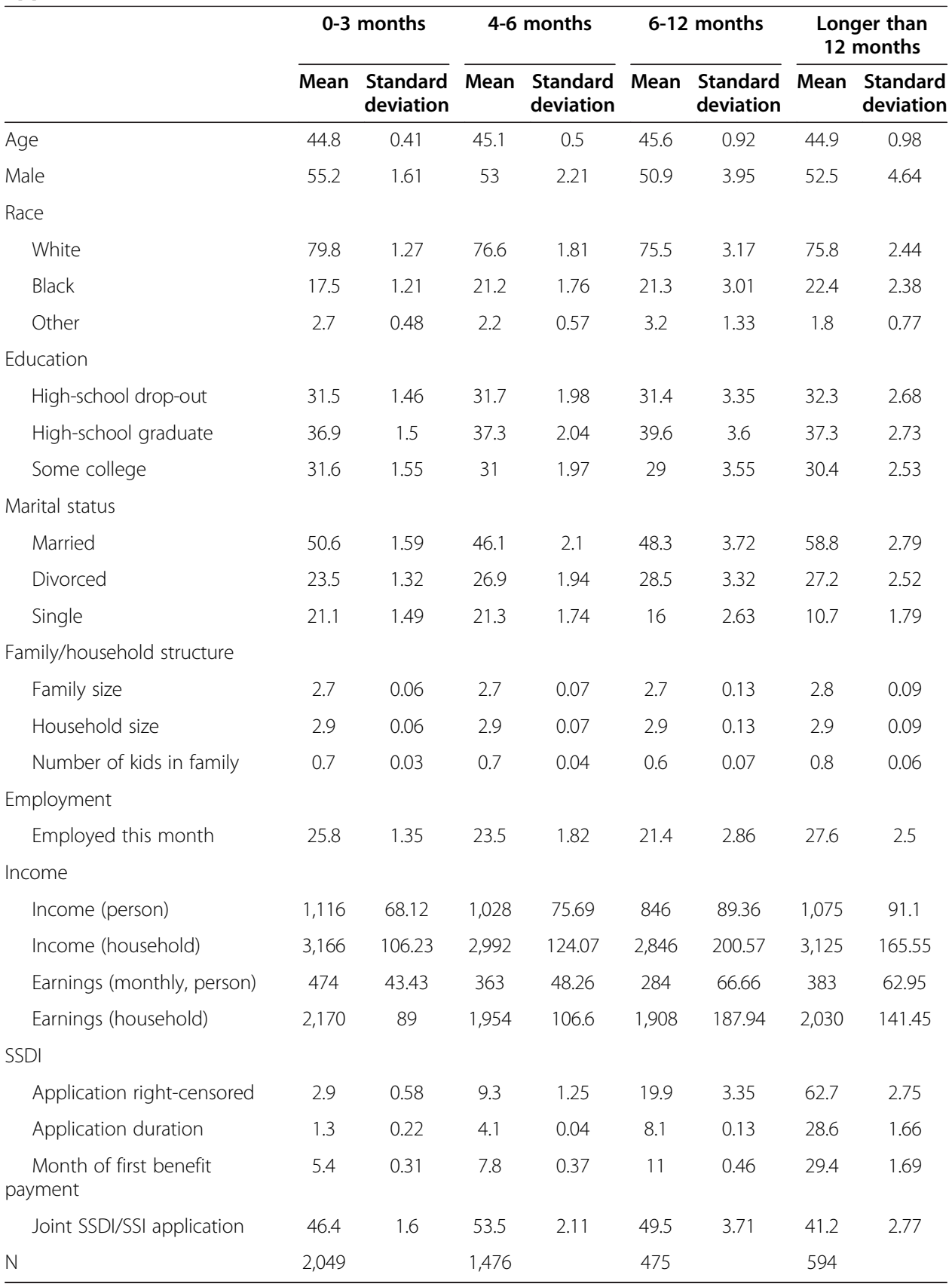

Specifically, we examine changes in household income and coping strategies of our sample across seven distinct periods related to the timing of the SSDI application, ranging from 20 months before application (approximating the economic status before disability onset) to 20 months after application ${ }^{17}$. Figure 2 describes changes in employment, earnings (whether or not the person is working), and total income over time at both the individual and household level. Not surprisingly, the percent of applicants employed decreases over time. The decrease in employment starts early, even at 8-10 months before application, not just at the time of application; this finding is consistent with Lindner (2013) who documents employment transitions of SSDI applicants. 
Table 6 The use of coping strategies, by application duration, at the month of application

\begin{tabular}{|c|c|c|c|c|c|c|c|c|}
\hline & \multicolumn{2}{|c|}{$0-3$ months } & \multicolumn{2}{|c|}{ 4-6 months } & \multicolumn{2}{|c|}{ 6-12 months } & \multicolumn{2}{|c|}{$\begin{array}{l}\text { Longer than } \\
12 \text { months }\end{array}$} \\
\hline & Mean & $\begin{array}{l}\text { Standard } \\
\text { deviation }\end{array}$ & Mean & $\begin{array}{l}\text { Standard } \\
\text { deviation }\end{array}$ & Mean & $\begin{array}{l}\text { Standard } \\
\text { deviation }\end{array}$ & Mean & $\begin{array}{l}\text { Standard } \\
\text { deviation }\end{array}$ \\
\hline \multicolumn{9}{|l|}{ Government transfers } \\
\hline SNAP recipiency & 16.9 & 1.1 & 19.4 & 1.6 & 20.6 & 3.0 & 19.2 & 2.3 \\
\hline Ul recipiency & 5.5 & 1.1 & 6.8 & 1.1 & 4.1 & 1.5 & 2.6 & 0.9 \\
\hline $\begin{array}{l}\text { Workers' compensation } \\
\text { recipiency }\end{array}$ & 5.7 & 0.7 & 6.9 & 1.1 & 7.8 & 2.0 & 9.6 & 1.7 \\
\hline \multicolumn{9}{|l|}{ Intra-family resources } \\
\hline \multicolumn{9}{|l|}{ Spousal Labor Supply } \\
\hline Employment & 63.1 & 2.0 & 61.5 & 2.9 & 57.6 & 5.6 & 66.0 & 3.4 \\
\hline Earnings & 2883 & 129 & 2719 & 134 & 2650 & 197 & 2587 & 159 \\
\hline \multicolumn{9}{|l|}{ Other financial resources } \\
\hline \multicolumn{9}{|c|}{ Borrowing from credit cards } \\
\hline Fraction & 16.0 & 1.1 & 18.5 & 1.7 & 19.1 & 2.8 & 16.9 & 2.1 \\
\hline Amount & 4278 & 493 & 2685 & 367 & 2237 & 493 & 3021 & 588 \\
\hline Home ownership & 60.0 & 1.6 & 57.2 & 2.1 & 51.4 & 3.7 & 62.2 & 2.7 \\
\hline \multicolumn{9}{|l|}{ Locational changes } \\
\hline Changed address & 3.4 & 0.5 & 5.5 & 0.9 & 2.7 & 1.2 & 5.0 & 1.2 \\
\hline $\mathrm{N}$ & 2049 & & 1476 & & 475 & & 594 & \\
\hline
\end{tabular}

Employment also continues to decline over time, but never goes to zero; 16 percent of the applicants are still employed 18-20 months after they apply for the disability program. Earnings decline over time as well; individual earnings declining the most (primarily because of the drop in employment), whereas household earnings and household income drop less severely.

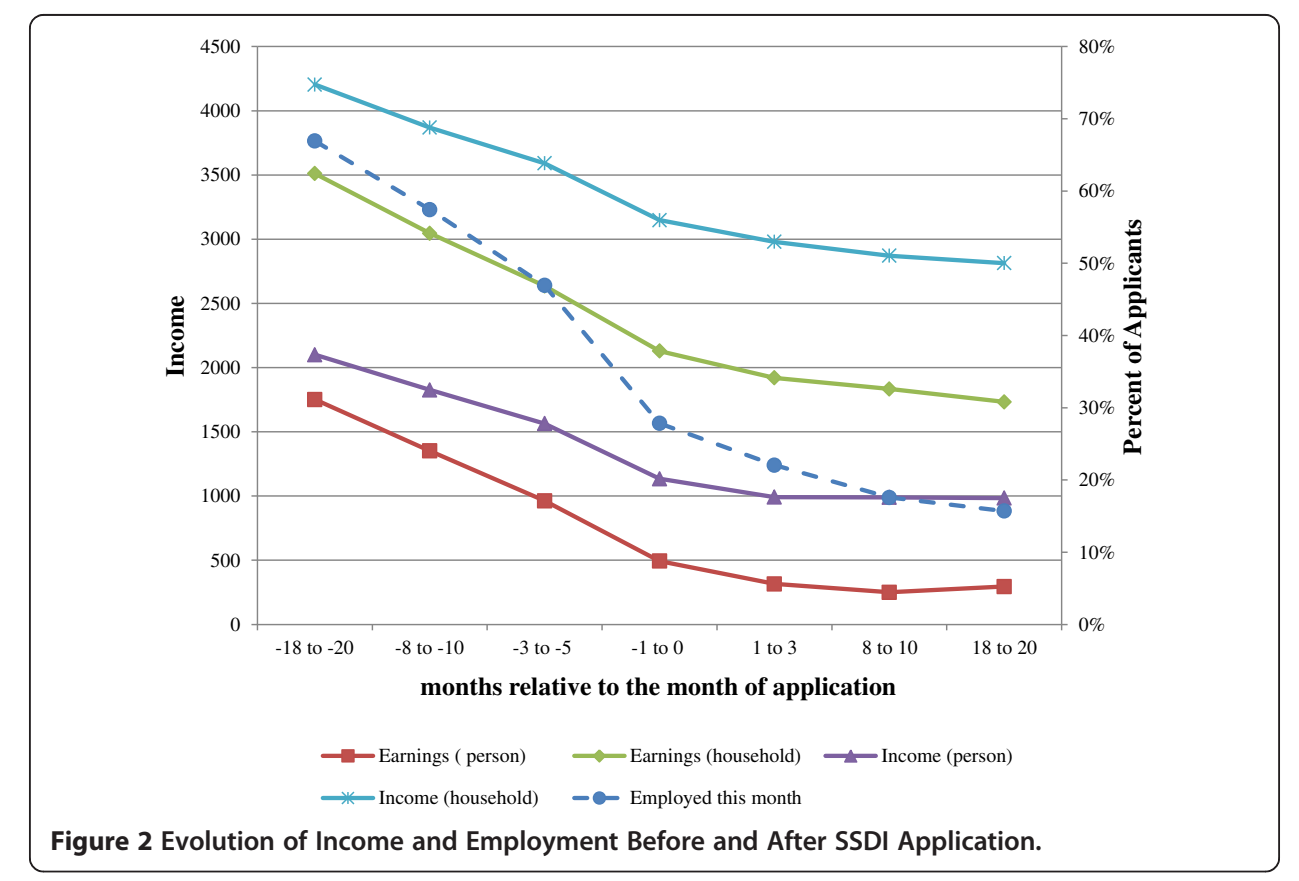




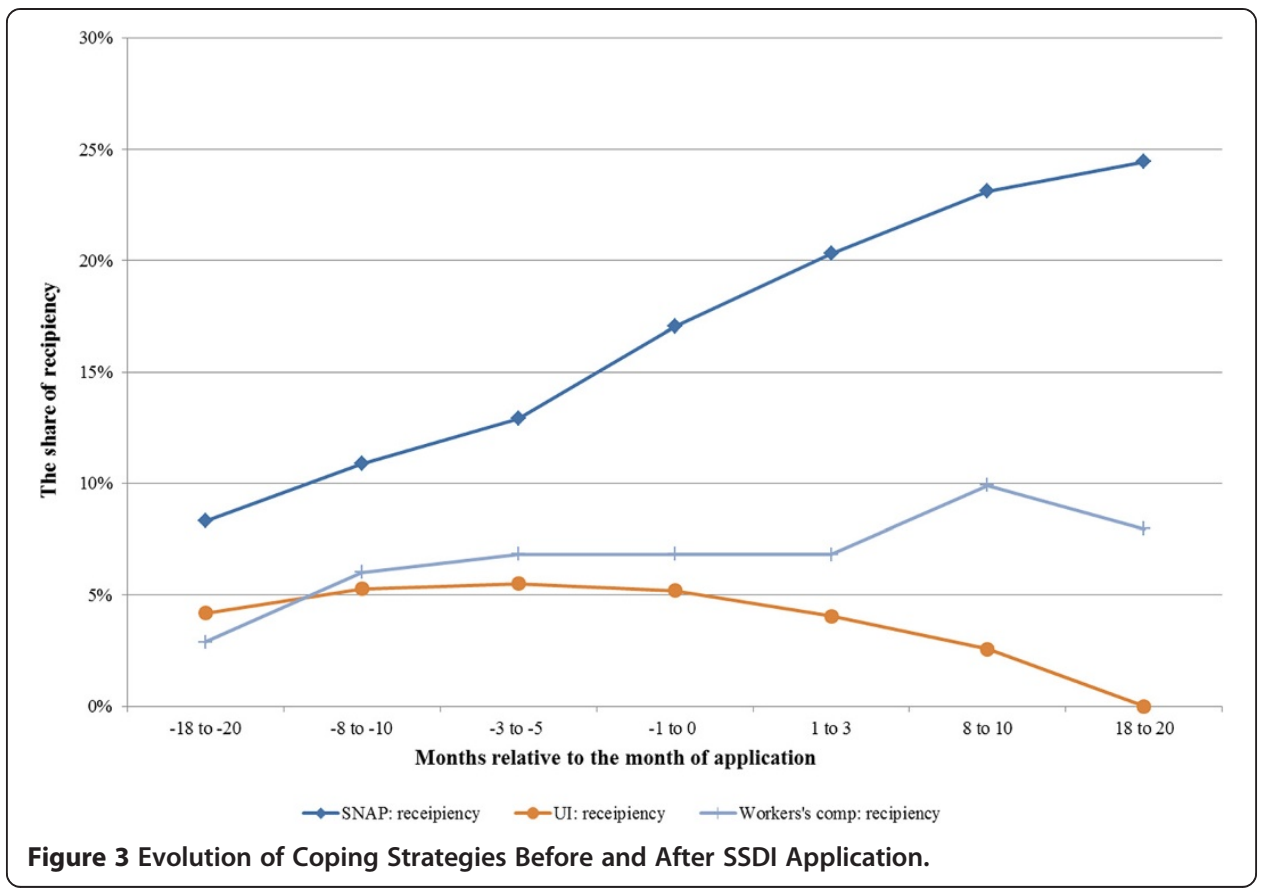

Along with this decrease in earnings and income comes an increase in needs-based assistance; SNAP recipiency increases dramatically over time (Figure 3). Unemployment insurance has a humped-shape over time, with more people receiving UI benefits between 10 months prior and their application, then decreasing over time as their application is reviewed and possibly UI benefits expire. The number of people receiving worker's compensation increases over time up to the $10^{\text {th }}$ month after application and then decreases slightly.

While not shown in the figures, we also find that home ownership declines, suggesting SSDI applicants could be using housing assets to support their consumption. In addition, the probability of changing address decreases over time. While applicants may borrow from credit cards to fund consumption while waiting, there is no significant correlation between borrowing from other financial resources and waiting time.

\section{Empirical methods}

The descriptive analysis above illustrates some interesting correlations between the wait time, demographics, and the use of certain coping strategies. However, the pattern may be confounded by the issue of selection, on either observable or unobservable characteristics. To explore whether and extent to which the length of wait time and other factors relate to certain coping strategies, we first estimate equations of the following form:

$$
\text { Strategy }_{i t}=\beta_{0}+\beta_{1} A W_{i}+\beta_{2} X_{i t}+\gamma_{t}+S_{t}+\varepsilon_{i t}
$$

where Strategy $y_{\text {it }}$ measures each of the five coping strategies indicated above, controlling for the actual total wait time $\left(A W_{i}\right)$, and individual characteristics such as age, race, education, gender, marital status, and family structure $\left(X_{i t}\right)^{18}$. We also control for secular and short-term changes in program participation and family structure by including a set of year indicator variables $\left(\gamma_{t}\right)$. We include a set of state dummies $\left(S_{t}\right)$ because the 
wait time for a SSDI award varies substantially depending on where the individuals live and, as highlighted in the public assistance program literature, the use of need-based programs varies substantially by region and state.

Using this regression approach, we analyze the relationship between outcomes and the wait time. In the first specification, we analyze Strategy $y_{i t=a}$, measuring the likelihood of using a coping strategy at the time of application as a function of total application duration $\left(A W_{i}\right)$, controlling for individual characteristics. This set of analyses sheds light on how the wait time is correlated with the initial coping strategy selection. Second, we analyze the outcome Strategy $y_{\text {it }}$ for all months of application as a function of total application duration $\left(A W_{i}\right)$. The results of this model represent the association between the application duration and the average use of a certain coping strategy.

These regressions shed light on the association between various coping strategies and applicants' waiting times, but they cannot address how people change their coping strategies as they face longer waiting times. For instance, research has demonstrated that a lack of information contributes to welfare program nonparticipation among eligibles (Coe 1983, Blaylock and Smallwood 1984, Hill 1990, Daponte et al. 1999, Wu 2009). Those who are eligible but do not take-up SNAP may also not appeal an initial SSDI denial due to the unfamiliarity of the program rules, which results in a shorter waiting time. To understand better how people change their coping strategies over the course of their waiting time, we next regress the use of a coping strategy on time since application, using waiting time fixed effects to control for unobserved heterogeneity between people with a shorter versus longer overall waiting time. Our regression equation is written as follows:

$$
\text { Strategy }_{i t}=\beta_{0}+\beta_{1} A W_{i t}+\beta_{2} A W_{i}+\beta_{3} X_{i t}+\gamma_{t}+S_{t}+\varepsilon_{i t}
$$

where we analyze Strategy $y_{\text {it }}$ as a function of time since application $\left(A W_{i t}\right)$, controlling for total application time $\left(A W_{i}\right)$. By adding total application duration fixed effects to the model, this approach explores the changes in the use of coping strategies since application given the length of the overall application duration.

This type of regression controls for heterogeneity in the use of coping strategies related to the overall waiting time, but it cannot distinguish between applicants reacting to an exogenously longer waiting time (e.g., because of fewer case workers) and applicants using a coping strategy to file an appeal, which increases their chance of being admitted into the program but also their overall waiting time. For instance, applicants with a spouse who can increase his or her work time and thereby contribute more to household income may be more inclined to appeal an initial denial. To address such endogeneity concerns, we employ an instrumental variable approach. Specifically, because the wait time varies substantially by the location of the applicants and his or her disability condition (see Table 1), we use the average wait time by state-year-stage to instrument for the actual waiting time, where stage refers to initial five-stage determination process.

The first stage estimates the effect of state-year-stage average wait time on the individual actual waiting time:

$$
A W_{i}=\beta_{0}+\beta_{1} S S W_{s s t}+\beta_{2} X_{i t}+\gamma_{t}+S_{t}+\varepsilon_{i t}
$$


where $S S W_{\text {sst }}$ is average state-year-stage wait time. As before, we include state and year fixed-effects in this regression.

In the second stage, the predicted value of individual waiting time from the first stage is substituted for actual waiting time.

$$
\text { Strategy }_{i t}=\beta_{0}+\beta_{1} \widehat{\mathrm{AW}}_{i}+\beta_{2} X_{i t}+\gamma_{t}+S_{t}+\varepsilon_{i t}
$$

where $\widehat{\mathrm{AW}}_{i}$ is the predicted waiting time. Because we include year and state fixed effects as well, identification is from within-state variation in the waiting time that does not reflect common changes across all states in a given year, for instance dues to business cycle conditions. The exclusion restriction requires such changes to be uncorrelated with other factors that affect the use of coping strategies. We believe that this assumption is justified because the identifying variation primarily comes from changes in the number of staff reviewing applications and fluctuations in the number of applications from year to year that are not common across all states.

The models described above only include the waiting time as a linear term. They do, however, address some of the non-linearity found in the descriptive section by examining behavior at both the first month of application and the average use of a coping strategy over the entire spell. We explored the potential use of quadratic term of the waiting time to capture further non-linearities. However, the quadratic term was in general not statistically significant in the reduced form and suffered from a weak instruments problem in the IV models (where we construct a squared term of average wait time by state-year-stage to instrument for the squared value of individual's wait time). There are several possible reasons why there is not a detectible role for nonlinearities in our regression models. The observed nonlinearities in Table 6 are not large relative to standard deviations; they could represent true changes over time or simply noise. Moreover, changes in other characteristics that we control for in our models may explain changes in the use of coping strategies by the wait time observed in the descriptive analysis. We therefore restrict our subsequent discussion to results for models that use only the wait time as a linear term.

\section{How is application duration related to the use of coping strategies?}

Table 7 summarizes regression results using an unbalanced sample, which includes both completed and right-censored observations ${ }^{19}$. Column (1) and (3) presents regression coefficients of linear probability models estimating equation (1) for the two regressions: month of initial application and all months of application. Column (2) and (4) presents IV results from equations (3) and (4) for month of application and all months of application, respectively. For the month of application (column 1), the IV measures whether applicants react to an unexpectedly change in the wait time by changing their initial coping strategy, during the first month of application. For all months of application (column 3), the IV measures how an unexpected change in the wait time is related to changes in coping strategies over the full course of the application.

Even if instruments are relevant, they might be weak. In that case, instrumental variable estimates may be inconsistent and imprecisely measured. Therefore, Table 7 also reports the first stage results from estimating equation (3) and the F statistic, which 
Table 7 Regression analysis: unbalanced sample

\begin{tabular}{|c|c|c|c|c|c|c|c|c|c|c|}
\hline \multirow[b]{3}{*}{ Coping strategies } & \multirow[b]{3}{*}{ Number of Obs } & \multirow{3}{*}{$\frac{\text { Column } 1}{\frac{\text { Application begin }}{\text { OLS }}}$} & \multirow[b]{3}{*}{ IV } & \multirow{3}{*}{$\frac{\frac{\text { Column } 2}{\text { Application begin }}}{\frac{\text { First stage }}{}}$} & \multirow[b]{3}{*}{ F-test } & \multirow{3}{*}{$\frac{\frac{\text { Column } 3}{\text { Application months }}}{\text { OLS }}$} & \multirow[b]{3}{*}{ IV } & \multirow{3}{*}{$\frac{\frac{\text { Column } 4}{\text { Application months }}}{\frac{\text { First stage }}{}}$} & \multirow[b]{3}{*}{ F-test } & \multirow{3}{*}{$\begin{array}{c}\text { Column } 5 \\
\text { Application duration FE } \\
\begin{array}{c}\text { Time since application } \\
\text { (months) }\end{array}\end{array}$} \\
\hline & & & & & & & & & & \\
\hline & & & & & & & & & & \\
\hline \multirow[t]{2}{*}{ Married } & 3477 & $0.151 *$ & 0.263 & $1.403 * * *$ & 48.49 & 0.098 & 0.281 & $2.530^{* * *}$ & 29.55 & -0.093 \\
\hline & & $(0.057)$ & $(0.464)$ & $(0.202)$ & & $(0.060)$ & $(0.334)$ & 0.46530 & & $(0.117)$ \\
\hline \multirow[t]{2}{*}{ Spousal employment } & 1784 & -0.114 & -0.313 & $1.740 * * *$ & 35.83 & -0.029 & -0.133 & $3.339^{* * *}$ & 22.27 & $0.318 *$ \\
\hline & & $(0.840)$ & $(0.692)$ & $(0.291)$ & & $(0.082)$ & $(0.368)$ & $(0.708)$ & & $(0.161)$ \\
\hline \multirow[t]{2}{*}{ Spouse earnings: level } & 1730 & -0.636 & -3.39929 & $1.749 * * *$ & 36.18 & 5.840 & 14.8879 & $3.356^{* * *}$ & 21.55 & 9.934 \\
\hline & & $(3.645)$ & (35.084) & $(0.291)$ & & $(5.101)$ & $(18.097)$ & $(0.723)$ & & $(7.709)$ \\
\hline \multirow[t]{2}{*}{ SNAP: recipiency } & 3477 & 0.042 & $0.902 *$ & $1.389 * * *$ & 46.24 & 0.051 & $0.785 *$ & $2.498^{* * *}$ & 28.98 & $0.422 * *$ \\
\hline & & $(0.058)$ & $(0.428)$ & $(0.204)$ & & $(0.057)$ & $(0.330)$ & $(0.464)$ & & $(0.133)$ \\
\hline \multirow[t]{2}{*}{ UI: recipiency } & 3477 & -0.023 & 0.06 & $1.389 * * *$ & 46.24 & $-0.022^{*}$ & 0.13 & $2.498^{* * *}$ & 28.98 & $-0.144^{* * *}$ \\
\hline & & $(0.021)$ & $(0.343)$ & $(0.204)$ & & $(0.010)$ & $(0.134)$ & $(0.464)$ & & $(0.043)$ \\
\hline \multirow[t]{2}{*}{ Workers's comp: recipiency } & 3477 & -0.024 & 0.104 & $1.389 * * *$ & 46.24 & $-0.043^{* *}$ & -0.101 & $2.498^{* * *}$ & 28.98 & $-0.176 * *$ \\
\hline & & $(0.024)$ & $(0.211)$ & $(0.204)$ & & $(0.015)$ & $(0.147)$ & $(0.464)$ & & $(0.067)$ \\
\hline \multirow[t]{2}{*}{ Changed address } & 3477 & 0.055 & -0.092 & $1.389 * * *$ & 46.24 & -0.011 & $-0.109 *$ & $2.498^{* * *}$ & 28.98 & $-0.083 * * *$ \\
\hline & & $(0.042)$ & $(0.244)$ & $(0.204)$ & & $(0.008)$ & $(0.047)$ & $(0.464)$ & & $(0.020)$ \\
\hline \multirow[t]{2}{*}{ Home ownership } & 3477 & -0.115 & -0.85 & $1.389 * * *$ & 46.24 & $0.152^{*}$ & -0.453 & $2.498^{* * *}$ & 28.98 & $-0.337 *$ \\
\hline & & $(0.064)$ & $(0.482)$ & $(0.204)$ & & $(0.067)$ & $(0.358)$ & $(0.464)$ & & $-(0.133)$ \\
\hline Whether borrowed & 3477 & 0.016 & 0.308 & $1.389^{* * *}$ & 46.24 & -0.001 & -0.166 & $2.498^{* * *}$ & 28.98 & 0.039 \\
\hline credit card loan & & $(0.058)$ & $(0.618)$ & $(0.204)$ & 46.24 & $(0.044)$ & $(0.305)$ & $(0.464)$ & 28.98 & $(0.133)$ \\
\hline
\end{tabular}

Significance Levels: ${ }^{* *} 1 \%$ le vel, ${ }^{* *} 5 \%$ level, ${ }^{*} 10 \%$ level. 
tests whether the coefficient of the instrument is zero. Column (5) report results regression results estimating equation (2) for regression of months since application.

Each row of the table presents different regression results for each coping strategy separately. Coefficients for binary variables are expressed as percentages. Table 7 presents the results from 55 (11 coping strategies x 5 estimation models) separate regression models.

With few exceptions, the association between using a coping strategy at the time of application and total application duration is largely absent (Table 7, Column 1). The one exception is being married: a one month longer application duration is associated with an almost 0.15 percent higher probability of being married. However, those who are married are not more likely to have a working spouse or higher income through the spouse. To the contrary, the coefficients for spousal employment and spousal earnings are negative and imprecisely measured. While SNAP recipiency is positively related to a longer application duration though not significantly different from zero, other coping strategies such as UI recipiency, and workers' compensation recipiency are negative, but insignificant and small. The lack of associations between any initial coping strategy and the final wait time suggests that applicants do not differ systematically in their initial use of coping strategies. The third column shows OLS results for all application months. We find that longer wait times are negatively associated with UI and workers' compensation benefit recipiency, but positively correlated with home ownership probability.

We then present results for the likelihood of using a coping strategy as a function of time since application, controlling for the overall application duration (Table 7, Column 5). We find that being married is positively associated with total application duration at the month of application, but is uncorrelated with the time since application, suggesting that being married is a precondition for people being able to sustain a longer application duration, and, not surprisingly, applicants do not get married in order to sustain their application. The role of a working spouse is further corroborated by the positive and significant coefficient for spousal employment. This suggests an added worker effect: as applicants remain out of the labor market for a longer time, their spouse starts working to balance lost household income. An alternative interpretation of the coefficient could be that individuals with an initially denied application whose spouse finds employment decide to prolong their application by filing an appeal. The coefficient implies that a three-month longer time since application is associated with about a one percent higher employment rate of a spouse. We revisit the interpretation of this coefficient when we discuss the instrumental variables estimation results.

The positive association between spousal employment and time since application also implies a positive association between spousal earnings and time since application, but the coefficient is not precisely estimated. We do not find significant differences for spousal earnings conditional on employment, suggesting that newly working spouses have similar earnings than those already working.

Turning to other income sources, one can see that SNAP recipiency is positively related to a longer time since application. As with spousal employment, these coefficients are consistent with two interpretations. First, applicants increase take-up as the application goes on, or second, initially rejected applicants decide to file an appeal if they can draw from these income sources. Interestingly, for UI and workers' compensation 
receipt, we observe negative coefficients, likely because people lose eligibility for these programs over time.

The last two significant coefficients concern where applicants live. The negative coefficient for a change in address suggests that applicants hold off relocating while they are in the midst of their SSDI application. However, homeowners - a majority (58 percent) of applicants - do seem more likely to sell their home as their application duration increases. These two findings seem contradictory. One way to reconcile these differences is that homeowners tap into their home equity to fund consumption during the application process, but renters do not move, perhaps because the money saved in monthly rent is not enough to justify the fixed costs of moving.

The IV estimates of the relationship between using a coping strategy at the time of application/all months of application and total application duration are summarized in Column 2 and Column 4 respectively. The first stage results show that the instrument tends to have the expected sign and is statistically significant - that is, average stateyear-stage waiting time are positively correlated to individual actual waiting time ${ }^{20}$. For instance, in the regression for spousal employment, a one month increase in average state-year-stage waiting time is predicted to increase individual actual waiting time by 3.4 months. The first stage results also show that the instrumental variable is strong with F-statistics over 10 (Staiger and Stock 1997).

The IV results put the findings from the last specification in perspective. First, they corroborate the positive relationship between the wait time and SNAP recipiency and the negative relationship between the wait time and an address change (when all months are considered). Second, IV coefficients for spousal employment are negative and insignificant, in contrast to the positive and significant coefficient for the time since application specification. These results together suggest that the association between spousal employment and the wait time is due to reverse causality: a higher spousal employment leads to a longer wait time because applicants can more easily appeal an initial denial when their spouse works. Such a relationship between the wait time and spousal employment is captured by the OLS regression but not by the IV regression. Third, for UI and workers' compensation, coefficients of the IV regressions are negative as coefficients of the time since application regression, but insignificant. For these coping strategies, a reverse causality explanation in combination with negative effects does not seem plausible, so the lack of significance for the IV coefficients mostly reflect larger standard errors for IV regressions. Demographic characteristics are correlated with the use of a certain coping strategy as one would expect (see Table 8$)^{21}$. For example, age is negatively correlated with using need-based programs and changing address, but positively correlated with homeownership and probability of being married. Minority, low-educated, female applicants, and those with children in the household are more likely to use need-based transfers to fund their consumption. Husbands of applicants are more likely to increase their employment as well as earnings during the application process than wives of applicants. College-educated applicants see the largest increase in spousal earnings, which could reflect assortive mating and a positive association in the market wages between spouses or the lower replacement rate SSDI benefits among higher earning households. Further, higher education is associated with more borrowing from credit cards, which likely reveals easier access to this channel of funding consumption after a disability onset. 
Table 8 Regression a nalysis: unbalanced sample

\begin{tabular}{|c|c|c|c|c|c|c|c|c|c|}
\hline \multirow[b]{2}{*}{ Covariates } & \multicolumn{9}{|c|}{ Outcome variable } \\
\hline & Married & $\begin{array}{c}\text { Spousal } \\
\text { employment }\end{array}$ & $\begin{array}{c}\text { Spouse earnings: } \\
\text { level }\end{array}$ & $\begin{array}{l}\text { SNAP: } \\
\text { recipiency }\end{array}$ & $\begin{array}{c}\text { UI: } \\
\text { recipiency }\end{array}$ & $\begin{array}{l}\text { Workers's comp: } \\
\text { recipiency }\end{array}$ & $\begin{array}{l}\text { Changed } \\
\text { address }\end{array}$ & $\begin{array}{c}\text { Home } \\
\text { ownership }\end{array}$ & $\begin{array}{l}\text { Whether borrowed- credit } \\
\text { card loan }\end{array}$ \\
\hline Time since & -0.093 & $0.318 *$ & 9.934 & $0.422 *$ & $-0.144^{* * *}$ & $-0.176^{* *}$ & $-0.830 * * *$ & -0.337 * & 0.039 \\
\hline application & $(0.117)$ & $(0.161)$ & (7.709) & $(0.133)$ & $(0.043)$ & $(0.067)$ & $(0.020)$ & $(0.133)$ & $(0.133)$ \\
\hline \multirow[t]{2}{*}{ Age } & $0.714^{* * *}$ & $-0.292^{*}$ & 2.793 & $-0.279^{* * *}$ & -0.027 & -0.062 & $-0.066 * * *$ & $0.781 * * *$ & 0.310 \\
\hline & $(0.089)$ & $(0.147)$ & $(6.664)$ & $(0.074)$ & $(0.032)$ & $(0.042)$ & $(0.014)$ & $(0.090)$ & $(0.083)$ \\
\hline \multirow[t]{2}{*}{ Male } & $9.354^{* * *}$ & $-8.229 * * *$ & $-873.104 * * *$ & $-6.015^{* * *}$ & 0.920 & $1.730^{*}$ & 0.219 & 0.116 & $-6.991^{* * *}$ \\
\hline & $(1.674)$ & $(2.363)$ & (118.913) & (1.395) & $(0.563)$ & $(0.868)$ & $(0.217)$ & $(1.767)$ & $(1.452)$ \\
\hline \multirow[t]{2}{*}{ Black } & -19.975 & -2.164 & -150.631 & $8.677^{* * *}$ & -0.122 & -0.871 & -0.048 & $-11.948^{* * *}$ & $-5.547 * *$ \\
\hline & $(2.268)$ & $(3.560)$ & (173.658) & $(1.931)$ & $(0.700)$ & $(0.956)$ & $(0.286)$ & $(2.341)$ & $(1.885)$ \\
\hline \multirow[t]{2}{*}{ Other } & -1.730 & -4.516 & 305.449 & 3.896 & 0.175 & 2.427 & -0.020 & -2.810 & -0.159 \\
\hline & (3.530) & $(4.986)$ & $(427.277)$ & $(3.207)$ & $(1.347)$ & $(2.249)$ & $(0.527)$ & $(4.108)$ & (3.589) \\
\hline High-school & 0.135 & $7.335 *$ & $321.987 * *$ & $-6.680 * * *$ & -0.387 & -1.156 & -0.149 & $12.819 * * *$ & $4.082 *$ \\
\hline graduate & $(2.283)$ & (3.352) & (122.496) & $(1.846)$ & $(0.703)$ & $(1.335)$ & $(0.293)$ & $(2.355)$ & $(1.790)$ \\
\hline \multirow[t]{2}{*}{ Some college } & $5.277 *$ & $12.569 * * *$ & $932.834 * * *$ & $-10.901 * * *$ & 0.113 & -1.085 & -0.297 & $16.983 * * *$ & $11.777^{* * *}$ \\
\hline & $(2.362)$ & $(3.409)$ & $(139.227)$ & $(1.823)$ & $(0.767)$ & $(1.227)$ & $(0.290)$ & $(2.367)$ & $(1.860)$ \\
\hline \multirow[t]{2}{*}{ Family size } & $0.212^{* * *}$ & -0.021 & 11.664 & $-0.065 * * *$ & $-0.007 *$ & -0.005 & -0.004 ** & $0.110^{* * *}$ & -0.015 \\
\hline & $(0.009)$ & $(0.014)$ & (63.503) & $(0.007)$ & $(0.003)$ & $(0.005)$ & $(0.001)$ & $(0.010)$ & $(0.008)$ \\
\hline Number of kids in & $-0.155^{* * *}$ & 0.015 & -108.576 & $0.139 * * *$ & 0.004 & 0.004 & $0.006 * *$ & $-0.145 * * *$ & 0.007 \\
\hline family & (0.013) & (0.019) & (83.587) & $(0.010)$ & $(0.004)$ & $(0.006)$ & $(0.002)$ & $(0.013)$ & $(0.012)$ \\
\hline \multirow[t]{2}{*}{ Widowed } & & & & $14.413 * * *$ & -2.056 & -2.022 & 0.439 & -5.579 & $15.711^{* * *}$ \\
\hline & & & & $(4.005)$ & $(1.308)$ & $(1.645)$ & $(0.577)$ & $(4.504)$ & (3.990) \\
\hline
\end{tabular}


Table 8 Regression a nalysis: unbalanced sample (Continued)

\begin{tabular}{|c|c|c|c|c|c|c|c|c|c|}
\hline \multirow[t]{2}{*}{ Divorced/separated } & & & & $22.667 * * *$ & 0.648 & -2.775 ** & $0.914^{* *}$ & $-15.870^{* * *}$ & $13.286^{* * *}$ \\
\hline & & & & $(1.876)$ & $(0.755)$ & $(1.001)$ & $(0.286)$ & $(2.308)$ & $(1.906)$ \\
\hline \multirow[t]{2}{*}{ Single } & & & & 18.785 & -0.833 & -3.905 & 0.193 & -9.766 & 8.381 \\
\hline & & & & $(2.246)$ & $(0.914)$ & $(1.074)$ & $(0.361)$ & $(2.787)$ & $(2.325)$ \\
\hline $\mathrm{N}$ & 4010 & 2026 & 1964 & 4010 & 4010 & 4010 & 4010 & 4010 & 4010 \\
\hline
\end{tabular}

Significance Levels: *** $1 \%$ le vel, ** 5\% level, ${ }^{*} 10 \%$ level. 
By estimating these relationships for an unbalanced sample, we allow individuals with potentially very long wait times to influence the results. However, since the wait time is, at least to some extent, endogenous due to the decision to appeal, and applicants with a longer application duration are more likely to have some non-observed application months due to right-censoring which may potentially create biases, we test the robustness of our results by estimating these relationships on a balanced panel. This limits our sample to applicants who have a final decision on their application filed during the SIPP panel, and cuts our sample size by 15 percent. Despite these cuts and the endogeneity concern, our findings are largely consistent between samples ${ }^{22}$. Interestingly, the IV coefficient for UI recipiency (using all months of application) is significant for this sample, which seems very plausible: applicants use UI benefits as a coping strategy as long as they qualify for them.

Finally, as our descriptive statistics show that applicants of the 1990s are significantly different from applicants of the 2000s, we also explore an interaction model with the period dummy interacting with the waiting duration. We find that compared to applicants of the1990s, applicants with longer wait-time of the 2000s are increasingly more likely to use SNAP and UI benefits to fund consumptions while waiting for SSDI benefits, and less likely to use workers' compensation, sell the house, or borrow from credit cards.

\section{Conclusions}

The direct financial consequences of a disability onset are dramatic - previous estimates suggest a 50 to 80 percent drop in earnings. Means-tested programs, tapping into assets, family assistance and lowering expenses are all potential ways in which one could cope with this income loss, especially before SSDI benefits kick in. While the relationship between the wait time and any particular initial or average coping strategies is largely absent, our findings suggest that SNAP is a very important coping mechanism for SSDI applicants over the course of the application. Those applicants with longer waiting durations are more likely to use SNAP benefits both as an initial and average coping strategy. This relationship has some direct policy implications. For instance, it implies that a reallocation of funds that decrease SSDI wait may decrease outlays for SNAP and therefore decreases the overall costs of reducing SSDI wait times. Thus, our findings highlight that such program interactions are important in understanding the full fiscal implications of changes to the SSDI program.

Another important finding is the relationship between SSDI waiting time and spousal employment for married individuals. An increase in the waiting time does not appear to increase the likelihood that an applicant's spouse works. The added-worker effect first hypothesized during the 1940's as a way for married households to cope with the widespread unemployment of the Great Depression - has had little support empirically. Our findings suggest that households do not try to self-insure in the case of disability onset, at least in the beginning of the disability spell. While Cullen and Gruber (2000) and Chen (2012) suggest that public insurance programs are crowding out the added worker effect for households facing unemployment or disability respectively, this crowding out is absent during the application period when applicants have not yet received benefits or even know if they will receive benefits. There are several potential reasons why we do not find an added worker effect: it could be that liquidity 
constraints are not binding during the waiting period (which seems unlikely given our findings related to SNAP), that spouses have weak labor force attachments that do not allow them to increase labor supply even if desired, or that spouses have limited time to work due to new caregiving responsibilities. Further examination as to why couples do not seem to self-insure against a disability onset in the short-term is warranted.

While we do not find that spouses increase their employment to cope with a longer wait time, our IV results in combination with our OLS results for spousal employment suggest the opposite: an increase in spousal employment leads to a longer waiting time. Thus working spouses are not providing insurance against the income lost due to a disability onset, but presumably they afford the household the opportunity for more time to appeal. If these repeated appeals result in getting on the disability benefit rolls, then this endogenous decision to appeal based on one's capability of funding consumption during the appeals process is an important consideration when thinking about the fairness of a public program with long and optional appeals processes.

Our study highlights that the wait time in itself is an important, but often overlooked, policy issue. Long wait times, especially because of the appeals process, put a high financial strain on people with health impairments. Therefore, reducing these wait times could be an important part of reforms aimed at making the program more effective. An alternative to reducing wait times would be to provide easily accessible short-term disability insurance benefits in combination with return-to-work programs, allowing more time for work inability screening. Such short-term benefits could alleviate the need of obtaining other income sources to sustain the application process or to be able to have a case been reconsidered by a judge.

\section{Endnotes}

${ }^{1}$ Gainful employment is defined here as earning over the Substantial Gainful Activity (SGA) amount, or more than $\$ 1,010(\$ 1,690)$ a month for non-blind (blind) disability beneficiaries in 2012 .

${ }^{2}$ Supplementary Security Income (SSI) cannot be considered as a coping strategy during the application determination process because SSI applications are processed like SSDI applications. Temporary Disability Insurance (TDI) is also excluded from the analysis because there is no information from the SIPP on receiving TDI benefits.

${ }^{3} \mathrm{We}$ also considered receiving financial assistance from family and friends, and withdrawals from savings or $401(\mathrm{k})$ accounts as coping strategies, but fewer than $2(0.5)$ percent of the sample reported these types of income and thus are not a focus of this study.

${ }^{4}$ Stage refers to the initial determination stage. We discuss this further in the next Section.

${ }^{5}$ In order to be covered by SSDI, one must have worked a minimum of 40 or (age-21) quarters overall and have earned half the credits in the last five years or since turning 21. While the rules always refer to "covered quarters," it has been a misnomer since 1978. Covered quarters are calculated by the amount one makes in a calendar year, not the amount of time one was employed. In 2012, earnings of $\$ 1,130$ are required to earn one quarter of coverage.

${ }^{6}$ Individuals may be terminated from the disability program due to medical recovery or by earnings that exceed the SGA under certain conditions. "Medical recovery" is 
determined through continuing disability reviews (CDRs), whose use has varied widely over time. Stapleton et al. (2010) find that only 4 percent of 1996 SSDI awardees had their benefits terminated for work in the first ten years in the program. Coe and Rupp (2013) find that approximately 1 percent of SSDI beneficiaries leave the rolls per year either due to work effort or medical recovery.

${ }^{7}$ Exceptions to rotational assignment include high-priority cases flagged as potential terminal illness cases.

${ }^{8}$ See http://www.ssa.gov/dibplan/dqualify5.htm (last accessed: 01/15/2014) for a description.

${ }^{9}$ In a few cases, the 831 files contain the information on the level of application stage that goes beyond the ALJ level. However, the quality of the data concerning these higher-level appeals decisions is questionable.

${ }^{10}$ For the purpose of our analysis, we include all months from the month of application to the month of final determination and calculate the average wait time using months included in the sample. This definition implies a longer wait time as compared to exact days. For instance, an applicant who filed on April 15, 2000 that is determined by June 15, 2000 has an application duration of two months but we include three months (April, May and June) as application months.

${ }^{11}$ See http://www.ssa.gov/policy/docs/statcomps/supplement/.

${ }^{12}$ The shift toward women seems somewhat larger in our sample than in official statistics. In the 2010 Statistical Supplement, 59 percent of all beneficiaries were male in the 1990s and 54 percent in the 2000s. One possibility for the stronger shift toward women in our sample could be that the matching rate to administrative records for men declined stronger over time than the matching rate for women.

${ }^{13}$ Part of this educational change may also reflect higher non-matching rates among SIPP surveys in the 2000s because individuals not matched to SSA records have on average a lower educational level.

${ }^{14}$ For some of coping strategies, we need information from topic modules of the SIPP. Therefore, the sample size changes due to the merge procedure.

${ }^{15}$ We focus on the use of SNAP rather the take-up of SNAP among eligible for two reasons. First, the asset information comes from the special topical module of the SIPP, which is asked infrequently (the maximum is once each year per panel with the timing varying substantially by SIPP panel). Second, there is a growing body of research pointing to measurement error in many SIPP variables that are critical to estimating public program eligibility (Strand et al. 2009, and Meyer et al. 2009). For robustness check, we also examine SNAP take-up among the eligible and the results are largely consistent with those focusing on SNAP recipiency. The results are available from authors upon request.

${ }^{16}$ The mover rate was between 12 and 30 percent per year, or about 1-2 percent per month, for the last decade (Ihrke and Faber 2012).

${ }^{17}$ It is worth noting that the sample becomes very small at the last time point because only those with longer waiting time are included.

${ }^{18}$ Because our descriptive statistics suggest that there is a U-shaped relationship between the actual wait time and some coping strategies, in sensitivity tests, we include a squared term of the actual wait time in our model and the results are largely similar. 
${ }^{19}$ The detailed regression results on each coping strategy using the balanced sample are available upon request.

${ }^{20}$ Coefficients are not always identical because of different samples used (e.g., only married applicants for spousal employment) or different covariates (marital status not needed for spousal employment). For the estimation that has being married as the outcome measure, the controls are different from other estimations because marital status are used as controls in other models.

${ }^{21}$ Table 8 describe all of the covariates included in the model, except state and year dummies.

${ }^{22}$ The results are available from authors upon request.

\section{Competing interest}

The IZA Journal of Labor Economics is committed to the IZA Guiding Principles of Research Integrity. The authors declare that they have observed these principles.

\section{Acknowledgements}

The research reported herein was pursuant to a grant from the U.S. Social Security Administration (SSA), funded as part of the Retirement Research Consortium (RRC). The findings and conclusions expressed are solely those of the authors and do not represent the views of SSA, any agency of the federal government, the RRC, Boston College, University of Washington, Dartmouth College, the Urban Institute, its board or its sponsors. The authors would like to thank Matthew Rutledge, Craig V. Thornton, participants at the APPAM fall research conference, the anonymous referee and editors for helpful comments. All errors are the authors'.

This paper was submitted to the IZA Journal of Labor Policy's call for papers on "Social Security Disability Benefits: Finding Alternatives to Benefit Receipt." Two special editors, David Wittenburg and Gina Livermore, were sponsored by the University of New Hampshire's Rehabilitation, Research, and Training Center on Employment Policy and Measurement, funded by the U.S. Department of Education (ED), National Institute on Disability and Rehabilitation Research (cooperative agreement no. H133B100030). Their comments do not necessarily represent the policies of ED or any other federal agency (Edgar, 75.620 (b)). The authors are solely responsible for all views expressed. Responsible editor: Gina Livermore

\section{Author details}

${ }^{1}$ School of Public Health, and NBER, University of Washington, 1959 NE Pacific Street, Seattle, WA 98195, USA. ²Urban Institute, 2100 M Street NW, Washington, DC 20037, USA. 'Dartmouth College, Geisel School of Medicine, 1 Rope Ferry Rd, Hanover, NH 03755, USA. ${ }^{4}$ Boston College Center for Retirement Research, 140 Commonwealth Ave, Chestnut Hill, MA 02467, USA.

Received: 15 October 2013 Accepted: 7 January 2014

Published: 30 Jan 2014

References

Allsup. 2010. "Allsup Analysis Finds 10 States Top List of Worst for Social Security Disability Insurance Backlogs". Allsup. com, 2010. Web. 01/09/2013.

Autor, D, and M Duggan. 2010. Supporting Work: A Proposal for Modernizing the U.S. Disability Insurance System. Washington, DC: Center for American Progress and the Hamilton Project.

Autor, D, N Maestas, KJ Mullen, and A Strand. 2011. "Does Delay Cause Decay? The Effect of Administrative Decision Time on the Labor Force Participation and Earnings of Disability Applicants". Working Paper 2011-258. Ann Arbor, Ml: Michigan Retirement Research Center Research.

Blaylock, JR, and DM Smallwood. 1984. Reasons for non-participation in the food stamp program. Western Journal of Agricultural Economics 9: 117-126.

Bound, J, RV Burkhauser, and A Nichols. 2003. "Tracking the Household Income of SSDI and SSI Applicants". In Worker Well-Being and Public Policy (Research in Labor Economics, Volume 22), ed. W Solomon, 113-158. Polachek: Emerald Group Publishing Limited.

Bound, J, T Waidmann, and S Lindner. 2010. "Reconciling Findings on the Employment Impact of Disability Insurance". Working Papers WP239. University of Michigan, Michigan Retirement Research Center.

Chen, SE. 2012. "Spousal Labor Supply Responses to Government Programs: Evidence from the Disability Insurance Program," Working Papers WP261. University of Michigan, Michigan Retirement Research Center.

Coe, RD. 1983. "Participation in the Food Stamp Program, 1979.". In Five Thousand American Families - Patterns of Economic Progress, 10, ed. GJ Duncan and JN Morgan, 121-177. Ann Arbor, MI: University of Michigan.

Coe, NB, and K Rupp. 2013. "Does Access to Health Insurance Influence Work Effort Among Disability Cash Benefit Recipients?" Working Paper 2013-10. Chestnut Hill, MA: Center for Retirement Research at Boston College.

Cullen, JB, and J Gruber. 2000. Does unemployment insurance crowd out spousal labor supply? Journal of Labor Economics 18(3): 546-572.

Dale, SB, and JM Verdier. 2003. "Elimination of Medicare's Waiting Period for Seriously Disabled Adults: Impact on Coverage and Costs". Issue Brief 660. New York: The Commonwealth Fund.

Daponte, BO, S Sanders, and L Taylor. 1999. Why do low-income households not use food stamps? Evidence from an experiment. Journal of Human Resources 34(3): 612-628. 
Dushi, I, and K Rupp. 2013. Disability shocks near retirement age and financial well-being. Social Security Bulletin 73(3): 23-43.

French, E, and J Song. 2009. "The Effect of Disability Insurance Receipt on Labor Supply", Working paper 2009-05. Chicago, IL: Federal Reserve Bank of Chicago.

Heckman, J. 1974. Shadow prices, market wages, and labor supply. Econometrica 42(4): 679-694.

Hill, DH. 1990. An endogenously-switching ordered-response model of information, perceived eligibility and participation in SSI. The Review of Economics and Statistics 72(2): 368-371.

Honeycutt, TC. 2004. Program and benefit paths to the social security disability insurance program. Journal of Vocational Rehabilitation 21: 83-94.

Ihrke, DK, and CS Faber. 2012. "Geographical Mobility: 2005 to 2010". Current Population Reports, 20-567. Washington DC: U.S. Census Bureau.

Lindner, S. 2013. From working to applying: employment transitions of applicants for disability insurance in the United States. Journal of Social Policy 42(2): 329-348.

Livermore, G, D Stapleton, and H Claypool. 2009. "Health Insurance and Health Care Access Before and After SSD Entry". Commonwealth Fund publication 1255. New York: The Commonwealth Fund.

Meyer, BD, and WKC Mok. 2013. "Disability, Earnings, Income and Consumption." NBER Working Paper No. 18869. Cambridge, MA: National Bureau of Economic Research.

Meyer, BD, WKC Mok, and JX Sullivan. 2009. "The Under-Reporting of Transfers in Household Surveys: Its Nature and Consequences." NBER Working Paper 15182. Cambridge, MA: National Bureau of Economic Research.

Riley, GF. 2006. Health insurance and access to care among social security disability insurance beneficiaries during the medicare waiting period. Inquiry 43(3): 222-230.

Schimmel, J, and DC Stapleton. 2012. The financial repercussions of new work-limiting health conditions for older workers. Inquiry 49(2): 141-163.

Social Security Administration. 2010. Annual Statistical Report on the Social Security Disability Insurance Program Chapter 7. "Beneficiaries Who Have Filed for Workers' Compensation or Public Disability Benefits : Social Security Administration". Paper presented at the Federal Committee on Statistical Methodology Research Conference, Washington, DC. Available: www.fcsm.gov/09papers/Strand_V-A.do accessed 01/15/2014.

Staiger, D, and JH Stock. 1997. Instrumental variables regressions with weak instruments. Econometrica 65(3): 557-586.

Stapleton, D, S Liu, D Phelps, and S Prenovitz. 2010. Work Activity and Use of Employment Supports Under the Original Ticket to Work Regulations: Longitudinal Statistics for New Social Security Disability Insurance Beneficiaries. Washington, DC: Mathematica Policy Research.

Strand, A, K Rupp, and PS Davies. 2009. "Measurement Error in Estimates of the Participation Rate in Means-Tested Programs: The Case of the US Supplemental Security Income Program for the Elderly".

Wu, AY. 2009. "Why Do So Few Elderly Use Food Stamps?" Working Paper 10.01. Chicago, IL: The Harris School of Public Policy Studies, The University of Chicago.

10.1186/2193-9004-3-1

Cite this article as: Coe et al: How do people with disabilities cope while waiting for disability insurance benefits? IZA Journal of Labor Policy 2014, 3:1

Submit your manuscript to a SpringerOpen ${ }^{\circ}$ journal and benefit from:

- Convenient online submission

- Rigorous peer review

- Immediate publication on acceptance

- Open access: articles freely available online

- High visibility within the field

- Retaining the copyright to your article

Submit your next manuscript at $\boldsymbol{\sim}$ springeropen.com 